\title{
Kreativitas Penciptaan Lirik Lagu Oleh Kelompok Musik Lembayung Senja
}

\author{
Deby Rima Aprisca \\ Moh. Muttaqin \\ Widodo
Alumni Jurusan Pendidikan Seni Musik, Fakultas Bahasa dan Seni, Universitas Negeri Semarang \\ debyrimaaprisca@gmail.com
}

\begin{abstract}
Abstrak
Kelompok musik Lembayung Senja adalah salah satu band indie yang berasal dari Kota Semarang. Lagu-lagunya banyak menggunakan lirik kiasan yang mengandung filosofis, membuat kelompok musik Lembayung Senja memiliki karakter tersendiri. Lagunya yang berjudul Sejuta Kenangan Di Kota Semarang dan Cerita Malam adalah lagu yang memiliki arti penting dalam perjalanan karir kelompok musik Lembayung Senja. Hal ini menjadikan rasa keingintahuan, bagaimana kreativitas dari penciptaan lirik lagu Sejuta Kenangan Di Kota Semarang dan Cerita Malam kelompok musik Lembayung Senja? Sedangkan tujuan yang akan dicapai dalam peneltian ini adalah untuk mengetahui, menganalisa, dan mendeskripsikan kreativitas penciptaan lirik lagu Sejuta Kenangan Di Kota Semarang dan Cerita Malam kelompok musik Lembayung Senja. Metode penelitian yang digunakan dalam penelitian ini adalah deskriptif kualitatif dengan pendekatan yang dilakukan yaitu pendekatan psikologi dan musikologis. Lokasi penelitian di basecamp kelompok musik Lembayung Senja yaitu di Jalan Taman Siswa Gang Tamansari 2 nomor 6, Sekaran, Gunungpati, Semarang. Teknik pengumpulan data antara lain: teknik observasi, teknik wawancara, teknik studi dokumen. Analisis data yang dilakukan antara: lain pengumpulan data, reduksi data, penyajian data, dan penarikan kesimpulan. Hasil penelitian ini menunjukan bahwa kelompok musik Lembayung Senja adalah kelompok musik yang kreatif, dengan membuat musik seperti ritme, melodi, harmoni, ekspresi (tempo dan dinamik) serta liriknya, berdasarkan dengan (1) kemampun berpikir, (2) keluwesan berpikir, (3) elaborasi yang baik dan tepat. Bentuk dan struktur lagu Sejuta Kenangan Di Kota Semarang dengan urutan kalimat A(a,a'), A(x, 'x'), B(b,b'), $\mathrm{B}\left(\mathrm{y}, \mathrm{y}^{\prime}\right), \mathrm{C}\left(\mathrm{c}, \mathrm{c}^{\prime}, \mathrm{c}^{\prime \prime}\right), \mathrm{C}\left(\mathrm{z}, \mathrm{z}^{\prime}\right)$. C(d) dan merupakan lagu 2 bagian sedangkan lagu Cerita Malam memiliki urutan kalimat $\mathrm{A}(\mathrm{a}, \mathrm{x}), \mathrm{A}\left(\mathrm{a}, \mathrm{x}^{\prime}\right), \mathrm{B}(\mathrm{b}, \mathrm{y}), \mathrm{B}\left(\mathrm{b}^{\prime}, \mathrm{y}^{\prime}\right), \mathrm{C}\left(\mathrm{c}, \mathrm{c}^{\prime}\right), \mathrm{C}\left(\mathrm{z}, \mathrm{z}{ }^{\prime}\right), \mathrm{C}\left(\mathrm{c}^{\prime}\right.$ ', c'"'), C(z',z'”) dan merupakan lagu 3 bagian.Dalam komposisi musiknya juga terbilang sederhana. Dengan progresi akord yang mudah, melodi yang variatif, pengembangan pola ritme, dan ekspresi musik yang pas, menjadikan kreativitas kelompok musik Lembayung Senja memiliki nilai lebih.
\end{abstract}

Kata Kunci : Kreativitas, Cipta, Musik, Lirik, Kelompok Musik Lembayung Senja.

\section{A. PENDAHULUAN \\ Latar Belakang Masalah}

Dalam hal bermusik, kreativitas sangatlah dibutuhkan dan penting karena tanpa ide-ide kreatif karya seni tidak akan terwujud. Berdasarkan pernyataan tersebut dapat diartikan bahwa bermusik sebagai bagian dari perilaku berkesenian yang pada dasarnya merupakan proses menyampaikan pesan, emosi, dan nilai kemanusiaan atau hasil tafsir pribadi, atau kelompok seniman dalam menyampaikan hasil karyanya melalui suara dalam bentuk ekspresi musikal.

Musik tidak hanya digunakan sebagai sarana hiburan. Dengan adanya lirik pada musik, penciptanya ingin menyampaikan makna dan pesan kepada setiap pendengarnya. Sehingga lewat lirik lagu, seorang pencipta lagu dapat berkomunikasi dengan para pendengarnya. Di dalam lirik lagu 
tersebut pencipta lagu dapat menyampaikan perasaan, pendapat, bahkan kejadian sehari-hari yang terjadi di dunia ini, sehingga banyak lagu-lagu yang mengangkat tema suatu kejadian atau peristiwa yang terjadi sehari-hari.

Salah satu kelompok musik yang kreatif dalam menciptakan musik beserta liriknya kelompok musik Lembayung Senja. Berdiri dari tahun 2011 sampai saat ini, kelompok musik Lembayung Senja sudah menciptakan 57 lagu. Ada 9 lagu dari kelompok musik Lembayung Senja yang sudah di record dan di sebarluaskan yaitu Sejuta Kenangan Di Kota Semarang, Cerita Malam, Keresahan, Putih Abu, Delkon Cinta, Mengingat Kita, Selamat Tidur, Bingkisan Lagu, Benar Dan Salah.

Diantara 9 lagu yang sudah disebarluaskan oleh kelompok musik Lembayung Senja, lagu Sejuta Kenangan Di Kota Semarang dan Cerita Malam sangat berarti dalam perjalanan karir kelompok musik Lembayung Senja. Penciptaan lirik dari kedua lagu tersebut menjadikan kelompok musik Lembayung Senja merupakan kelompok musik yang kreatif hal ini dikarenakan Navis menciptakan lirik tersebut dengan sesuai dengan ciri-ciri dari kreativitas. Kreativitas dalam bidang seni tumbuh dalam diri seorang penulis, pelukis, penyair, musisi, dan para seniman. Kreativitas sebagai kemampuan umum untuk menciptakan sesuatu yang baru, memberikan gagasan-gagasan baru yang dapat diterapkan untuk memecahankan masalah, atau sebagai kemampuan untuk melihat hubungan-hubungan baru antara unsur-unsur yang sudah ada sebelumnya (Munandar, 2009: 25).

Kreativitas sendiri memiliki ciri-ciri seperti yang ditemukan oleh Guilford (dalam Ghufron, 2010: 106) bahwa faktor penting yang merupakan ciri kreativitas adalah kelancaran berpikir, keluwesan berpikir, dan elaborasi. Ketiga unsur tersebut berkaitan dengan apa yang di ciptakan oleh Navis dalam membuat lirik lagu beserta musiknya. Karena kedua lagu tersebutlah kelompok musik Lembayung Senja menjadi dikenal luas oleh masyarakat di Semarang khususnya kalangan remaja. Salah satu daya tarik dari kedua lagu tersebut terdapat pada lirik lagu yang bahasanya dibuat puitis dan pesannya filosofis.

Dari latar belakang masalah di atas, maka penulis tertarik untuk meneliti dan menuliskannya ke dalam bentuk tulisan ilmiah berupa skripsi, dengan judul: "Kreativitas Penciptaan Lirik Lagu Oleh Kelompok Musik Lembayung Senja". Tujuan penelitian ini adalah untuk mengetahui, menganalisis, dan mendeskripsikan kreativitas kelompok musik Lembayung Senja dalam menciptakan lirik lagu.

\section{B. METODE PENELITIAN}

Penelitian ini menggunakan metode deskriptif kualitatif, sedangkan pendekatannya menggunakan pendekatan musikologis dan pendekatan psikologi.teknik pengumpulan data yang digunakan adalah observasi yang digunakan untuk mengetahui lokasi basecamp kelompok musik Lembayung Senja, wawancara utnutk mendapatkan data tentang sejarah berdirinya kelompok musik Lembayung Senja, profil personil kelompok musik Lembayung Senja, kreatifitas dalam menciptakan lirik, serta studi dokumen untuk mengkaji data yang sudah ada dari dokumen arsip, catatan-catatan lapangan, dan rekaman CD audio visual. Sedangkan analisis data menggunakan analisis isi yang bertujuan untuk menganalisa, menjelaskan, dan mendeskripsikan kreativitas ritme, melodi, harmoni, ekspresi serta lirik lagu yang sudah diciptakan oleh kelompok musik Lembayung Senja.

\section{HASIL DAN PEMBAHASAN \\ 1. HASIL}

\section{Gambaran Umum Lokasi Penelitian}

Sekaran merupakan salah satu kelurahan di Kecamatan Gunungpati. Luas wilayah Sekaran adalah 490.718 ha. Wilayah Kecamatan Gunungpati terletak di bagian selatan Kota Semarang, berbatasan langsung dengan Ungaran. Masyarakat yang tinggal di Kelurahan Sekaran sebagian besar masih bermata pencaharian petani dan pedagang. Namun setelah didaerah ini didirikan sebuah universitas yaitu IKIP (Institut Keguruan dan Ilmu Pendidikan) yang sekarang menjadi Universitas Negeri Semarang pada tahun 1965, mata pencaharian masyarakatnya lebih bervariasi seperti penjual makanan, usaha loundry, usaha rumah kelontong. Daerah Sekaran sekarang menjadi daerah yang cukup berkembang. Hutan dan perkebunan yang dulunya memenuhi daerah Sekaran sekarang sudah banyak dibangun perumahan, kos-kosan dan tempat menjual makanan.

Penduduk Sekaran umumnya adalah suku Jawa dan menggunakan bahasa Jawa sebagai bahasa sehari-hari. Di wilayah Kelurahan Sekaran Kecamatan Gunungpati terbagi dari 26 RT dan 7 RW dengan jumlah 6.241 jiwa. Laki-laki 3.533 jiwa, sedangkan perempuan 2.708 jiwa.

Agama yang dianut oleh masyarakat Sekaran adalah Islam. Hal ini dibuktikan dengan banyaknya kegiatan keislaman seperti pengajian dan rebana. Di Sekaran juga terdapat 7 buah masjid dan 20 buah mushola

Sekaran sebagai daerah yang yang ditempati oleh kampus Universitas Negeri Semarang terdapat berbagai macam seni pertunjukan. Seni pertunjukan yang ada meliputi Seni Tari, Seni Musik Modern, Ketoprak, Wayang Kulit, Campur Sari, Rebana.

\section{Kelompok Musik Lembayung Senja}

Kelompok musik Lembayung Senja merupakan kelompok musik indie yang ada di Semarang. Kelompok musik ini terbentuk pada 
tanggal 11 November tahun 2011, saat sekumpulan mahasiswa Jurusan Seni Musik Universitas Negeri Semarang (UNNES) sedang membutuhkan biaya untuk menyambung hidupnya, karena umumnya dari mereka adalah anak kos. Personil awal kelompok musik Lembayung Senja terbentuk adalah Bella Monica Paula (vokalis), Galech Roso Anggoro (keyboardis), Budi Setiawan (bassis), Bagus Eko Retnadi (drummer), dan Navis Ponco Aji (gitaris). Banyaknya masalah dan perubahan kehidupan masing-masing personilnya, kelompok musik Lembayung Senja mengalami perubahan personil yang sekarang tepatnya tahun 2016 Brianda Sakti sebagai vokalis, Navis sebagai gitaris, Dodi Candra sebagai keyboardis, Bagus sebagai drummer dan Zaky Iktaro yang hanya sebagai personil additional serta Galech sebagai manajer.

Lembayung dalam pengertiannya terjadi pada waktu sore antara pukul 17.00 - 17.30 atau disebut waktu berakhirnya senja. Menurut Kamus Besar Bahsa Indonesia (KBBI), Lembayung itu sendiri memiliki arti merah jingga, sebuah warna yang terlihat ketika matahari hampir terbenam. Lembayung Senja merupakan salah satu periode yg dipercaya para personil sebagai filosofis "pergantian waktu" dalam kehidupan manusia. Nama Lembayung Senja diambil karena menurut mereka suanana paling indah dan paling menyenangkan yang mereka lewati setiap harinya adalah waktu senja.

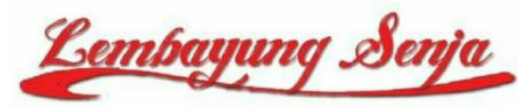

Logo Kelompok Musik Lembayung Senja (Sumber: Dokumentasi Lembayung Senja tahun 2012)

Lagu-lagu yang mereka bawakan biasanya lagu-lagu top 40 Indonesia atau masih membawakan lagu orang, yang diantaranya seperti : Dewa 19, Adera, Sheila On 7, Tulus, dan lain sebagainya.

Navis selaku gitaris kelompok musik Lembayung Senja terdorong untuk melakukan inovasi dari segi pengemasan musik dalam penampilan kelompok musik Lembayung Senja. Inovasi tersebut berupa musik akustik yang ditambah dengan nuansa musik digital. Musik digital tersebut dihasilkan oleh instrumen pukul. Musik akustik digital itu diharapkan dapat merubah pandangan musik akustik yang biasanya identik dengan cajon sebagai alat musik pukul.

Dengan adanya musik digital tersebut pengemasan musik dari kelompok musik Lembayung Senja dirasa lebih terdengar menjadi musik yang lebih modern. Kelompok musik Lembayung Senja dalam perkembangannya mengalami perubahan personil. Pada awal mula pembentukannya kelompok musik Lembayung Senja menjadikan posisi Bella pada vokalis, Budi pada bassist, Bagus pada drummer, Navis pada gitaris, dan Atenk pada keyboardis. Namun sekarang sudah tidak lagi karena adanya keinginan Bella sebagai personil yang harus menyelesaikan tugas kuliahnya, dan Budi yang sampai harus pulang ke kampung halamannnya setelah ia lulus dari perkuliahan untuk bekerja dan melanjutkan cita-citanya serta adanya ketidakfokusan dalam menjalaskan dua bidang sekaligus sehingga menjadikan Atenk harus memanajeri kelompok musik Lembayung Senja. Sekarang kelompok musik Lembayung Senja dilanjutkan oleh Brianda sebagai vokalis, Navis sebagai gitaris, Bagus sebagai drummer, dan Dodi sebagai keyboardis.

Kelompok musik Lembayung Senja telah membuat 57 buah lagu. Namun tidak semua lagu yang kelompok musik Lembayung Senja ciptakan direkam dan disebarluaskan kepada masyarakat. Kelompok musik Lembayung Senja memiliki 9 buah lagu yang liriknya ditulis oleh Navis dan diaransemen bersama personil lain serta sudah mereka rekam dan bisa dinikmati oleh masyarakat diantaranya Sejuta Kenangan Di Kota Semarang, Cerita Malam, Hidup Itu Masalah, Putih Abu-Abu, Mengingat Kita, Keresahan, Benar Dan Salah, Delkon Cinta, Bingkisan Lagu.

\section{Kreativitas Kelompok Musik Lembayung Senja}

Kreativitas kelompok musik Lembayung Senja dalam menciptakan lirik tentu berhubungan juga dengan beberapa unsur musiknya seperti : ritme, melodi, harmoni, ekspresi (tempo dan dinamik). Guildford (dalam ghufron, 2010:106) menemukan bahwa faktor penting yang merupakan ciri dari kreativitas adalah kelancaran berpikir, keluwesan berpikir, dan elaborasi. Ketiga hal tersebut di kaitkan dengan beberapa unsur musik lagu Sejuta Kenangan Di Kota Semarang dan Cerita Malam sekaligus penciptaan liriknya. Berikut merupakan penjelasannya :

Ritme

Ritme adalah suatu urutan rangkaian gerak yang terbentuk dari sekelompok bunyi dan diam dengan bermacam-macam lama waktu atau panjang pendeknya, membentuk pola irama bergerak menurut pulsa dalam ayunan birama (Jamalus 1981: 58), sedangkan pola ritme adalah pola nilai not atau panjang bunyi suatu komposisi musik yang sejalan dengan lagu (melodi) (Banoe 2003: 339).

Ritme yang ada di lagu Sejuta Kenangan Di Kota Semarang memiliki pengembangan ritme. Terdapat dua pola ritme pada lagu Sejuta Kenangan Di Kota Semarang, diantaranya adalah:

Bagian bait :

Motif ritme A

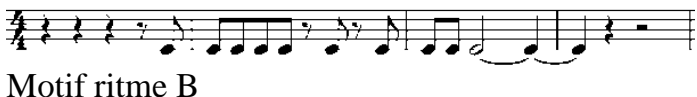

Motif ritme $\mathrm{B}$ 


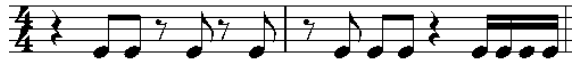

Motif ritme B1

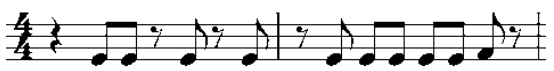

Motif ritme B2

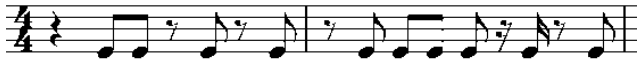

Setelah menganalisa motif ritme pada bagian awal lagu, dapat ditentukan pada bagian bait adalah AB-B1-B2 dan mengalami pengulangan sebanyak satu kali. Sedangkan pada Bagian Reff motif ritmenya yaitu:

Motif ritme $\mathrm{C}$

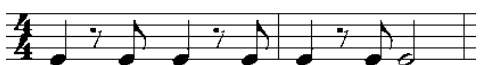

Motif ritme D

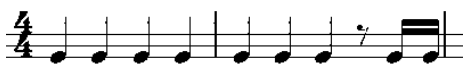

Motif ritme D1

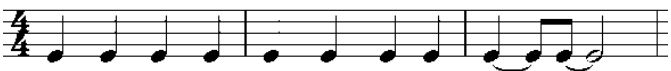

Motif ritme E

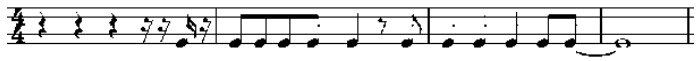

Setelah menganalisa bagian reff, dapat ditentukan pola pada bagian bagian reff ini terdapat empat motif ritme. Pola ritmenya adalah C-D-D1-C-D-

D1-E.

Terdapat sembilan pola ritme pada lagu Cerita Malam, diantaranya adalah:

Bagian bait

Motif A

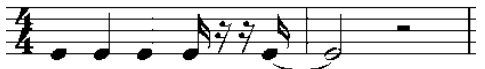

Motif B

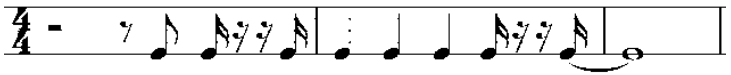

Setelah menganalisa motif ritme pada bagian awal lagu, dapat ditentukan pada bagian bait adalah A$B$ dan mengalami pengulangan sebanyak empat kali. Sedangkan pada bagian bridge motif ritmenya yaitu:

Motif C

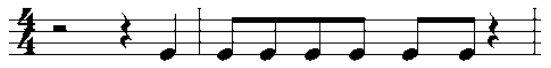

Motif D

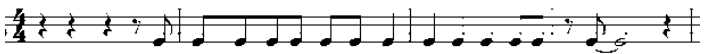

Motif D1

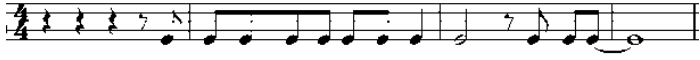

Setelah menganalisa motif ritme pada bagian bridge, adalah C-D-C-D1 dan tidak mengalami pengulangan. Sedangkan pada bagian reff motif ritmenya yaitu:

Motif E

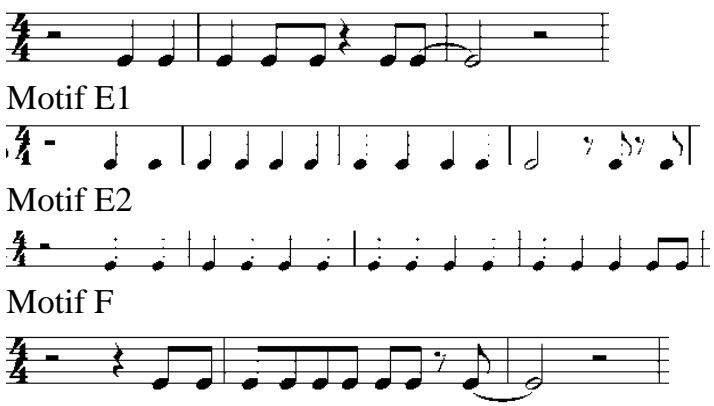

Setelah menganalisa motif ritme pada bagian reff, dapat ditentukan pada bagian bait yaitu E-F-E1-EF-E2 dan tidak mengalami pengulangan.

\section{Melodi}

Melodi adalah tinggi rendahnya nada yang membentuk lagu yang dinyanyikan sesuai titinadatitinada dari notasi lagu tersebut, panjang pendeknya suku kata dan kata dari lirik lagu bergantung pada nilai titinada-titinada dan tanda istirahat dalam notasi lagu (Joseph 2011: 57).

Range atau jarak suara pada lagu Sejuta Kenangan Di Kota Semarang tidak begitu luas. Meskipun lagu Sejuta Kenangan Di Kota Semarang memiliki range suara yang tidak begitu luas, namun pada birama ke 5 dan 17 jarak nada sangat tajam meloncat naik yaitu dari e1 sampai ke d2.

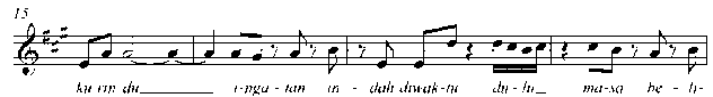

Hal kreatif lainnya pada lagu Sejuta Kenangan Di Kota Semarang adalah pada bagian reff. Bagian reff ini terdapat range nada yang kadang naik dan kadang turun.

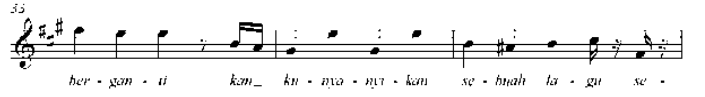

Lagu Cerita Malam tidak jauh berbeda dengan lagu Sejuta Kenangan Di Kota Semarang. Hal ini terbukti dari melodi yang dibuat dari birama $1-8$ sama dengan melodi pada birama $9-16$ sederhana. Hal ini bertujuan agar lagu Cerita Malam mudah di hafal oleh para pendengarnya.

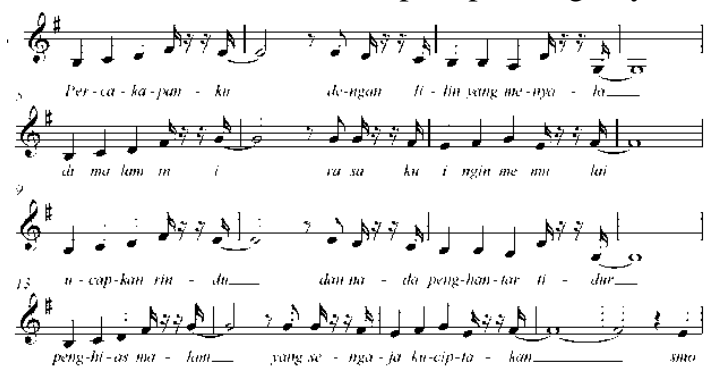

Harmoni 
Harmoni mempunyai arti keselarasan, dapat dikatakan juga bahwa harmoni adalah keselarasan antara nada yang satu dengan nada-nada yang lainnya yang memberikan nuansa yang estetis untuk indra pendengaran manusia. Harmoni juga masih erat hubungannya dengan istilah akor dan progresi dalam dunia musik (Banoe 2003: 180).

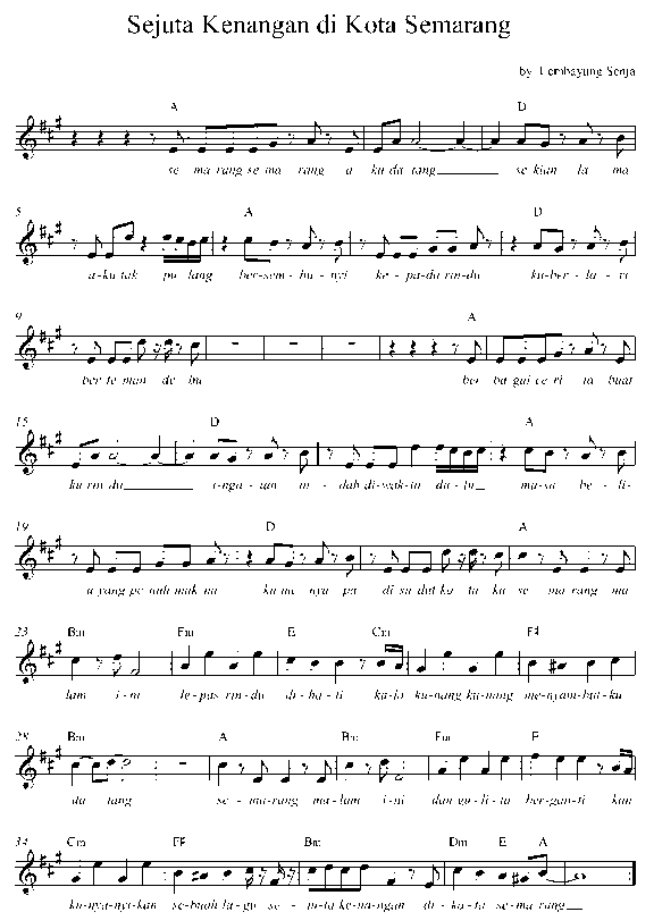

Di dalam menciptakan progresi akord lagu Cerita Malam, tahapan yang dilakukan Navis tidak berbeda jauh saat ia membuat progresi akord lagu Sejuta Kenangan Di Kota Semarang. Ia juga membuat progresi akord bersamaan dengan melodi yang di buatnya sehingga terdengar pas. Berikut merupakan progresi akord lagu Cerita Malam :

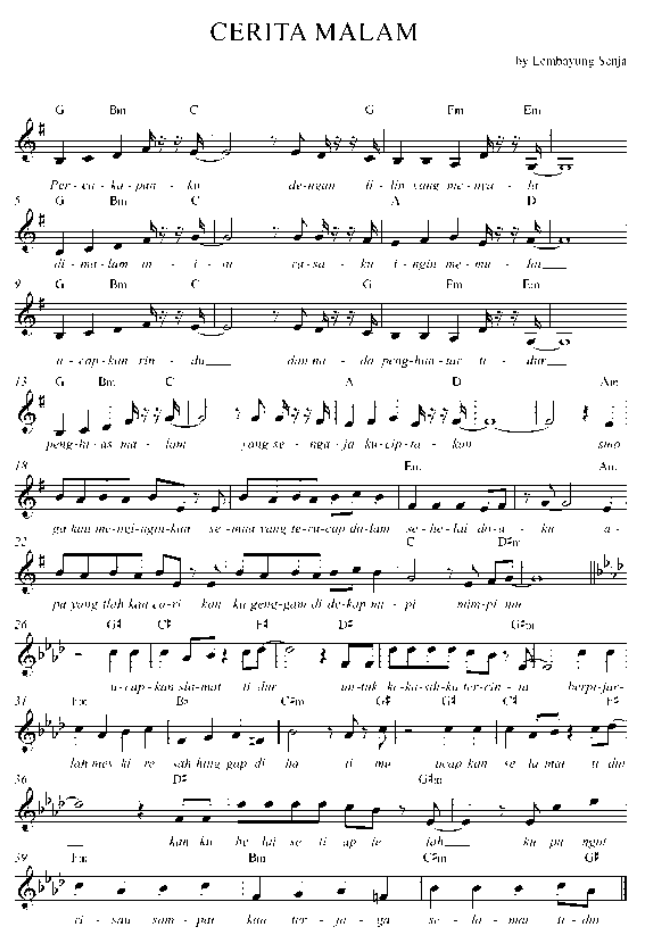

Tempo

Menurut Joseph (2012: 59), definisi tempo adalah tingkat kecepatan suatu lagu dengan perubahan kecepatannya dalam musik. Bentuk kreativitas tempo pada lagu Sejuta Kenangan Di Kota Semarang, bagian awal lagu atau introduksi sampai akhir lagu dimainkan dalam tempo Andante $(\mathrm{MM}=60)$ yang artinya seperti orang berjalan biasa.

Pada lagu Cerita Malam, dari lagu bagian awal sampai akhir lagu dimainkan dalam tempo Maestoso ( $\mathrm{MM}=90$ ) yang artinya khidmad dan agung.

\section{Dinamik}

Menurut Joseph (2012: 62), definisi dinamik adalah tingkat kuat lembut suatu lagu dengan perubahan kuat lembutnya dalam musik. Lagu Sejuta Kenangan Di Kota Semarang dan Cerita Malam mempunyai dinamik yang sama yaitu pada bait awal lagu dinamiknya yaitu piano yang artinya lembut, sedangkan pada bait reff lagu Sejuta Kenangan Di Kota Semarang dan Cerita Malam adalah mezzo forte yang artinya setengah (agak) kuat. Kedua lagu tesebut dibuat pelan karena memang isi dari lagunya bukanlah suasana yang bahagia melainkan suasana yang sedih.

Lirik

Untuk mengetahui dan menyelaraskan pandangan penikmat musik, serta mengetahui isi makna yang terkandung dalam lirik lagu Sejuta Kenangan Di Kota Semarang, maka dari itu langkah selanjutnya akan dituliskan lirik sebagai proses pembahasan. 
Semarang Semarang aku datang

A Sekian lama aku tak pulang

Bersembunyi kepada rindu

Kuberlari berteman debu

(b)

Berbagi cerita buatku rindu

Masa beli yang penuh warna

Ku menyapa disudut kotaku

Semarang malam ini

Lepas rindu dihati

C datang (c"')

Semarang malam ini

menyambutku

Dan gulita berganti

Kan kunyanyikan sebuah lagu

Sejuta kenangan dikota Semarang

Lagu Sejuta Kenangan Di Kota Semarang merupkan lagu dengan 2 bagian. Dalam lagu Sejuta Kenangan Di Kota Semarang terdapat urutan kalimat A (a, a'), A (x, x'), B (b, b'), B (y, y'), C (c, c', c', ), C (z, z'), C (d). Dalam susunan ini tidak terdapat pengulangan pada bagian A dan B. Namun pada bagian $\mathrm{C}$ terdapat pengulangan satu kali.

Keterangan: a dan a' = pertanyaan kalimat A

$$
\mathrm{x} \text { dan } \mathrm{x}^{\prime}=\text { jawaban kalimat } \mathrm{A}
$$

b dan $\mathrm{b}^{\prime}=$ pertanyaan kalimat $\mathrm{B}$

y dan $y^{\prime}=$ jawaban kalimat B

c, c' dan c', = pertanyaan kalimat C

$\mathrm{z}$ dan $\mathrm{z}^{\prime}=$ jawaban kalimat $\mathrm{C}$

$\mathrm{d}=$ jawaban kalimat $\mathrm{C}$ (dengan

Lagu Cerita Malam berisi tentang kerinduan, doa dan ditutup dengan ucapan selamat tidur. Lagu ini secara umum juga bercerita tentang pengandaian dan berpesan untuk tetap bersemangat kepada siapa saja agar tetap kuat dalam menjalani kehidupannya.

Percakapanku dengan lilin yang menyala (a)

A

Dimalam ini rasaku ingin memulai

(x)

Ucapkan rindu dan nada penghantar tidur

(a')

Penghias malam yang sengaja kuciptakan (x')

Bridge :

Semoga kau menginginkan semua yang

B

terucap

Dalam sehelai doaku

Apa yang tlah kau cari

Kan ku genggam di dekap mimpimiтріти (y')

\begin{tabular}{|c|c|c|}
\hline & Reff : & \\
\hline & Ucapkan slamat tidur & (c) \\
\hline & Untuk kekasih tercinta & $\left(c^{\prime}\right)$ \\
\hline $\mathrm{C}$ & Berpijarlah meski resah & (z) \\
\hline & Hinggap dihatimu & $\left(z^{\prime}\right)$ \\
\hline & Ucapkan slamat tidur & $(\mathrm{c} ")$ \\
\hline & Kan kubelai setiap lelah & $\left(c^{\prime \prime \prime}\right)$ \\
\hline & Kupungut risau & $\left(z^{\prime \prime}\right)$ \\
\hline & Sampai kau terjaga, & $r\left(\mathrm{z}^{\prime \prime \prime}\right)$ \\
\hline
\end{tabular}

Lagu Cerita Malam merupakan lagu dengan 3 bagian. Dalam lagu Cerita Malam terdapat urutan kalimat A (a, x), A (a', x'), B (b, y), B (b', y'), C (c, c'), C (z, z'), C (c'”, c'"'), C (z', z'"'). Dalam susunan ini tidak terdapat pengulangan pada bagian A, B, dan C. Namun setelah bagian A, B dan C selesai dinyanyikan, bagian $\mathrm{B}$ dan $\mathrm{C}$ kembali lagi dinyanyikan.

Keterangan: $\mathrm{a}=$ pertanyaan kalimat $\mathrm{A}$,

$\mathrm{x}=$ jawaban kalimat $\mathrm{A}$

$\mathrm{a}^{\prime}=$ pertanyaan kalimat $\mathrm{A}$,

$\mathrm{x}^{\prime}=$ jawaban kalimat $\mathrm{A}$

$\mathrm{b}=$ pertanyaan kalimat $\mathrm{B}$,

$\mathrm{y}=$ jawaban kalimat $\mathrm{B}$

$\mathrm{b}^{\prime}=$ pertanyaan kalimat B,

$\mathrm{y}^{\prime}=$ jawaban kalimat B

c dan c' = pertanyaan kalimat $\mathrm{C}$,

$\mathrm{z}$ dan $\mathrm{z}^{\prime}=$ jawaban kalimat $\mathrm{C}$

c' dan c',' = pertanyaan kalimat $\mathrm{C}$,

z' dan z', = jawaban kalimat C

\section{PEMBAHASAN \\ Ritme}

Lagu Sejuta Kenangan Di Kota Semarang dan Cerita Malam yang di ciptakan oleh Navis memiliki ciri kreativitas seperti menurut Guilford (dalam Ghufron, 2010: 106) bahwa faktor penting yang merupakan ciri kreativitas adalah kelancaran berpikir, keluwesan berpikir, dan elaborasi. Kelancaran berpikir dalam membuat ritme tersebut bahwa Navis hanya membutuhkan waktu setidaknya 30 menit dalam menciptakan ritme lagu Sejuta Kenangan Di Kota Semarang dan Cerita Malam. Sedangkan keluwesan berpikir serta elaborasinya adalah lagu Sejuta Kenangan Di Kota Semarang memiliki 5 motif ritme dengan 2 motif ritme yang mengalami pengembangan ritme. Sedangkan lagu Cerita Malam mempunyai 9 motif pola ritme dengan 2 pengembangan pola ritme. Kedua lagu tersebut diciptakan sedemikian rupa untuk menjadikan lagu Sejuta Kenangan Di Kota Semarang dan Cerita Malam terdengar lebih variatif.

\section{Melodi}

Melodi lagu Sejuta Kenangan Di Kota Semarang dan Cerita Malam juga memiliki ciri kreativitas dari Guilford (dalam Ghufron, 2010: 106). Sama seperti halnya dengan ritme, kelancaran berpikir dan keluwesan Navis dalam menciptakan 
melodi kedua lagu tersebut adalah dengan menciptakan melodi yang tidak terlalu rumit meskipun pada bagian tertentu pada lagu Sejuta Kenangan Di Kota Semarang memiliki jarak nada yang sangat tajam pada birama ke 5 dan 17 yaitu dari e1 sampai d2. Sedangkan pada lagu Cerita Malam, dibuat sangat sederhana yaitu birama ke 18 diulang pada bagian birama ke 9-16. Elaborasi dalam menciptakan melodi kedua lagu tersebut bertujuan agar lagu Sejuta Kenangan Di Kota Semarang dan Cerita Malam lebih easy listening dan mudah untuk diingat.

\section{Harmoni}

Harmoni/akord lagu Sejuta Kenangan Di Kota Semarang dan Cerita Malam juga memliki ciri kreativitas dari Guilford (dalam Ghufron, 2010, 106). Dilihat dari kreativitas harmoni/akord, kelancaran berpikir, keluwesan berpikir dan elaborasi dalam membuat akord lagu Sejuta Kenangan Di Kota Semarang dan Cerita Malam adalah dengan membuat akord yang sederhana yang dibuat saat ritme dan melodinya sudah dibuat. Progresi akord kedua lagu tersebut sengaja dibuat sederhana jadi dapat membangun suasana sesuai dengan pesan yang akan disampaikan.

Tempo

Tempo yang diciptakan oleh Navis memiliki ciri kreativitas yang sama seperti ritme, melodi dan harmoni yang sudah dibahas sebelumnya. Bahwa kelancaran berpikir dan keluwesan berpikir Navis dalam menentukan tempo pada lagu Sejuta Kenangan Di Kota Semarang tidaklah sulit. Tempo lagunya adalah Andante ( $\mathrm{MM}=60$ ) yang berarti seperti orang yang berjalan biasa. Elaborasinya bahwa Navis ingin menjadikan lagu ini terdengar mendayu sehingga sesuai dengan liriknya yang berisikan tentang kesedihan.

Sedangkan kelancaran berpikir dan keluwesan berpikir pada lagu Cerita Malam sengaja temponya dibuat dengan tempo Maestoso ( $M M=90$ ) yang berarti khidmad atau agung, sehingga elaborasi pada lagu Cerita Malam sesuai dengan isi liriknya yang mengenai kerinduan.

\section{Dinamik}

Dinamik lagu Sejuta Kenangan Di Kota Semarang dan Cerita Malam juga memeilki ciri kreativitas seperti kelancaran berpikir, keluwesan berpikir dan elaborasi. Kelancaran dan keluwesan berpikir pada lagu Sejuta Kenangan Di Kota Semarang dan Cerita Malam dibuatnya dinamika keduanya mempunyai dinamik yang sama yaitu piano yang berarti lambat di bagian awal lagu dan mezzo forte yang berarti setengah (agak) kuat pada bagian bridge dan reff. Elaborasinya kedua lagu tersebut dapat mencapai klimaks dan emosi dapat tersampaikan dengan baik oleh pendengarnya.

Lirik

Diciptakannya lirik lagu Sejuta Kenangan Di Kota Semarang dan Cerita Malam memiliki ciriciri kreativitas. Yang dilakukan oleh Navis dalam menciptakan lirik lagu sesuai kelancaran berpikir bahwa Navis mampu membuat lirik dari banyak ide yang datang kepadanya. Dari keluwesan berpikirnya menjelaskan tentang bagaimana Navis dapat menulis lirik dengan secara spontan, Navis juga bisa mengekspresikan semua yang ia rasakan melalui sebuah tulisan. Serta elaborasinya dalam penciptaan kedua lagu tersebut bahwa lirik yang Navis tulis selanjutnya di kembangkan menjadi sebuah lagu yang musiknya dibuat sesuai dengan isi dari lirik itu sendiri.

Lagu Sejuta Kenangan Di Kota Semarang merupakan lagu dengan 2 bagian. Lirik yang diciptakan oleh Navis berisi tentang kerinduannya terhadap Kota Semarang yang memberinya banyak sekali kenangan sewaktu ia kuliah. Lagu tersebut terinspirasi dari mantan kekasihnya yang dahulu memberikan banyak kenangan. Lirik ini ditulis oleh Navis secara spontan saat inspirasi itu datang. Lagu Sejuta Kenangan Di Kota Semarang merupakan lagu yang memliki rima diakhir tiap baitnya.

Berbeda dengan lagu Sejuta Kenangan Di Kota Semarang, lagu Cerita Malam merupakan lagu dengan 3 bagian. Lirik lagu ini juga ditulis oleh Navis. Lirik ini menceritakan tentang kerinduan pada seorang kekasih, dengan memberikannya doa terbaik serta mengucapkan selamat tidur di bagian akhir liriknya. Lagu Cerita Malam juga memiliki rima ditiap akhir bait liriknya.

\section{PENUTUP Simpulan}

Berdasarkan hasil penelitian yang memfokuskan pada "Kreativitas Penciptaan Lirik Lagu Sejuta Kenangan Di Kota Semarang dan Cerita Malam Kelompok Musik Lembayung Senja", maka peneliti dapat mengemukakan suatu simpulan sebagai berikut : kelompok musik Lembayung Senja merupakan kelompok musik yang kreatif dalam menciptakan lirik dalam lagunya. Dengan membuat lirik yang puitis dan mengandung makna filosofis, kelompok musik Lembayung Senja memiliki karakter yang kuat dalam setiap lagu yang diciptakannya.

Bentuk kreativitas musik dari kelompok musik Lembayung Senja dapat dilihat dari berbagai elemen-elemen musik yang didalamnya terdapat 3 ciri yaitu kelancaran berpikir, keluwesan berpikir, dan elaborasi. Dalam hal kreativitas ritme, kelancaran berpikir dalam menciptakan ritme, Navis mampu membuat ritme lagu Sejuta Kenangan Di Kota Semarang dalam waktu kurang lebih 30 menit. Keluwesan berpikirnya, Navis dapat menciptakan rimis pada lagu Sejuta Kenangan Di Kota Semarang dengan jumlah 5 motif pola ritme dan ada 2 pola ritme yang mengalami pengembangan. Dan elaborasinya mampu membuat lagu Sejuta Kenangan Di Kota Semarang menjadi lagu dengan pengembangan 
pola ritmenya. Serta kelancaran berpikir Navis saat membuat ritme lagu Cerita Malam yaitu dapat membuatnya dengan waktu kurang lebih 30 menit, keluwesan berpikirnya yaitu dapat membuat ritme yang variatif dengan jumlah 6 motif pola ritme dan ada 2 motif yang mengalami pengembangan pola ritme, elaborasinya dapat menjadikan lagu Cerita Malam yang menarik.

Di lihat dari subjek kreativitas melodi, kelancaran berpikir dan keluwesan berpikir dalam menciptakan melodi pada lagu Sejuta Kenangan Di Kota Semarang adalah Navis dapat menciptakan range melodi yang variatif, elaborasi pada pembuatan lagu Sejuta Kenangan Di Kota Semarang menjadikan lagu tersebut easy listening. Sedangkan pada lagu Cerita Malam, kelancaran dan keluwesan berpikirnya adalah tedapat pengulangan melodi. Elaborasinya adalah lagu Cerita Malam dapat lebih mudah dihafal oleh pendengarnya, lalu dilihat dari kreativitas harmoni/akord, kelancaran berpikir, keluwesan berpikir dan elaborasi dalam membuat akord lagu Sejuta Kenangan Di Kota Semarang adalah dengan membuat akord yang sederhana yang dibuat saat ritme dan melodinya sudah dibuat.

Sedangkan kelancaran berpikir, keluwesan berpikir dan elaborasi dalam membuat akord lagu Cerita Malam juga sama seperti yang dilakukan saat membuat akord Sejuta Kenangan Di Kota Semarang.

Terakhir kreativitas ekspresi dalam tempo, kelancran berpikir dan keluwesan berpikir dalam menentukan tempo pada lagu Sejuta Kenangan Di Kota Semarang tidaklah sulit. Tempo lagunya adalah Andante ( $\mathrm{MM}=60$ ) yang berarti seperti orang yang berjalan biasa. Elaborasinya bahwa lagu ini terdengar mendayu sehingga sesuai dengan liriknya yang berisikan tentang kesedihan. Sedangkan kelancran berpikir dan keluwesan berpikir pada lagu Cerita Malam sengaja temponya dibuat dengan tempo Maestoso ( $\mathrm{MM}=90$ ) yang berarti khidmad atau agung, sehingga elaborasi pada lagu Cerita Malam sesuai dengan isi liriknya yang mengenai kerinduan., (5) dinamik, kelancaran dan keluwesan berpikir pada lagu Sejuta Kenangan Di Kota dan Cerita Malam dibuatnya dinamika keduanya mempunyai dinamik yang sama yaitu piano yang berarti lambat di bagian awal lagu dan mezzo forte yang berarti setengah (agak) kuat pada bagian bridge dan reff. Elaborasinya kedua lagu tersebut dapat mencapai klimaks dan emosi pendnegarnya.

Sedangkan ciri-ciri kreativitas yang dilakukan oleh Navis dalam menciptakan lirik lagu yaitu ada (1) Kelancaran berpikir, Navis mampu membuat lirik dari banyak ide yang datang kepadanya. (2) Keluwesan berpikir, dengan menulis lirik secara spontan, Navis bisa mengekspresikan semua yang ia rasakan melalui sebuah tulisan. (3) Elaborasi, lirik yang Navis tulis selanjutnya di kembangkan menjadi sebuah lagu yang musiknya dibuat sesuai dengan isi dari lirik itu sendiri. Bentuk dan struktur lagu Sejuta Kenangan Di Kota Semarang dengan urutan kalimat $\mathrm{A}\left(\mathrm{a}, \mathrm{a}^{\prime}\right), \mathrm{A}\left(\mathrm{x}, \mathrm{x}^{\prime}\right), \mathrm{B}\left(\mathrm{b}, \mathrm{b}^{\prime}\right), \mathrm{B}\left(\mathrm{y}, \mathrm{y}^{\prime}\right)$, $\mathrm{C}\left(\mathrm{c}, \mathrm{c}^{\prime}, \mathrm{c}^{\prime}\right.$ '), $\mathrm{C}\left(\mathrm{z}, \mathrm{z} \mathrm{y}^{\prime}\right) . \mathrm{C}(\mathrm{d})$ dan merupakan lagu 2 bagian sedangkan lagu Cerita Malam memiliki urutan kalimat $\mathrm{A}(\mathrm{a}, \mathrm{x}), \mathrm{A}\left(\mathrm{a}^{\prime}, \mathrm{x}^{\prime}\right), \mathrm{B}(\mathrm{b}, \mathrm{y}), \mathrm{B}\left(\mathrm{b}^{\prime}, \mathrm{y}^{\prime}\right)$, $\mathrm{C}\left(\mathrm{c}, \mathrm{c}^{\prime}\right), \quad \mathrm{C}\left(\mathrm{z}, \mathrm{z}^{\prime}\right), \quad \mathrm{C}\left(\mathrm{c}^{\prime \prime}, \mathrm{c}^{\prime \prime},\right), \quad \mathrm{C}\left(\mathrm{z}^{\prime \prime}, \mathrm{z}^{\prime},{ }^{\prime}\right)$ dan merupakan lagu 3 bagian.

\section{Saran}

Berdasarkan hasil penelitian di atas, saran bagi kelompok musik Lembayung Senja adalah agar terus berkarya dalam membuat lagu dan meningkatkan krativitasnya lagi dalam menciptakan musik serta lirik di setiap lagu-lagu ciptaanya sehingga masyarakat dapat selalu mengapresiasi lagu-lagunya, serta mengembangkan musikalitasnya melalui hal-hal baru yang lebih kreatif lagi sehingga bisa bertahan dan lebih diterima oleh masyarakat luas.

\section{DAFTAR PUSTAKA}

Banoe, Pono. 2003. Kamus Musik. Yogyakarta: Kanisius Yogyakarta.

Ghufron, M. Nur., dkk. 2010. Teori-teori Psikologi. Jogjakata: Ar-Ruzz Media.

Joseph, Wagiman. 2011. Teori Musik I. Buku Ajar. Universitas Negeri Semarang.

2012. Teori Musik II. Semarang:

Universitas Negeri Semarang.

Kamus Besar Bahasa Indonesia. 2003. Depdiknas: Balai Pustaka.

Munandar, Utami. 2009. Pengembangan Kreativitas Anak Berbakat. Jakarta : Rineka Cipta

Kristyana, L., \& Suharto, S. (2014). Singing as a Strategy to Enhance the Ability to Speak for Early Childhood. Harmonia: Journal Of Arts Research And Education, 14(2), 123-130. doi:http://dx.doi.org/10.15294/harmonia.v14i2.329 3

Suharto, S.(1997). Musik dan Bahasa. Media, 20(4), 94-104

Suharto, S. (2011). Music And Language: A Stress Analysis of English Song Lyrics. Harmonia: Journal Of Arts Research And Education, 5(3). doi:http://dx.doi.org/10.15294/harmonia.v5i3.821

Suharto, S.(1991). BayanganNada sebagai Materi bagi Pembelajar Musik Pemula. Media FBS IKIP Semarang, 18 